\title{
Hold the Drones: Fostering the Development of Big Data Paradigms through Regulatory Frameworks
}

\author{
Robert Spousta and Steve Chan \\ Dr. Steve Chan Center for Sensemaking, Pacific-Asia Institute for Resilience \& Sustainability, Swansea University's Network \\ Science Research Center and Hawaii Pacific University, Swansea, Wales, U.K., Honolulu, Hawaii, USA
}

\begin{abstract}
This paper explores the effect of policy for civil unmanned aircraft systems on the development of national capabilities to conduct pervasive remote sensing in a Big Data Paradigm. We employ historical hindcasting of trends for comparably transformative technologies to gain insights into the role of regulation in the growth of strategic capabilities. In the context of these historical lessons, we trace the proliferation of unmanned aircraft, from their early use in military operations, to the wide variety of contemporary civil uses that have emerged. Most generally speaking, we analyze a sampling of the complex dynamics impacting the development of regulations for UAS (unmanned aircraft system) operations and explore how the optimized integration of these systems can bolster economic prosperity, national security, and individual resilience. We find that while such systems have tremendous potential for enhancing collective well-being and driving innovation in various scientific research, public service, and commercial endeavors, challenges associated with building comprehensive regulatory frameworks and public policies for their use has been a significant blind spot introducing brittleness and reducing opportunities for decision maximization.
\end{abstract}

Key words: Big data, complexity, pervasive remote sensing, resilience, unmanned aircraft system.

\section{Introduction}

Pervasive remote sensing is a significant enabling capability for addressing a host of complex challenges in a BDP (big data paradigm) [1]. In turn, the rise of UAS is the primary driver of the transition from satellite-based remote sensing to a pervasive remote sensing capability, and represents an area of rapidly evolving technology around the world. The proliferation of civil UAS represents a watershed moment for the field of remote sensing in particular, and Collaborative Big Data Analytics in general. While the United States has enjoyed a relative monopoly on such technology for military applications in the first decade of the 21 st century, the slow development of a regulatory framework for their broader domestic use represents a blind spot that has hampered the nation's ability to maintain a qualitative edge over their broader use.

Corresponding author: Robert Spousta, Chief of Staff, research fields: collaborative big data analytics, complexity, resilience. E-mail: spousta@mit.edu.
Only by incorporating a wide variety of social and technical considerations into its regulatory framework, can the U.S. maximize the global benefit of civil UAS. These considerations range from the potential for misuse of UAS platforms and the significance of individual air rights, to the latent brittleness of next-generation communication infrastructures that rely upon a particular frequency of the radio spectrum that is highly sensitive to atmospheric conditions (e.g., $\mathrm{Ka}$ Band). The current gap in U.S. policy with regard to UAS represents both a lost commercial economic opportunity and a potential erosion of national security.

In this paper, we demonstrate how the development of policy and regulation regarding UAS impacts the U.S. at a national strategic level, in particular its ability to gather and leverage data. We begin in Section 2 by establishing a systemic context for the impact of policy on the advancement of transformative technology through historical hindcasting of automobile manufacturing and space 
exploration. We go on in Section 3 to survey past and present implementation of UAS, and in Section 4, we compare national and international legal precedents which may bear relevance for UAS regulation. We conclude in Section 5 that while current UAS policy is negatively impacting the economy and security of the U.S., such a trend is reversible.

\section{From the Road to Space: Systemic Context for Transformative Technology}

To appreciate the influence of policy on the nation's ability to fully leverage UAS technology, it is illuminating to hindcast similar historical parallels. In particular, we take automobile manufacturing and space exploration as two areas which exemplify the importance of sustained innovation and forward-looking policy development. In both of these cases, we see that large investments fueled—initially—significant U.S. accomplishments, followed by a decrease in progressive momentum perpetuated by a mutually interactive combination of lax regulatory policy and industry malaise. The resulting lack of sustained innovation in both areas offered footholds for international competitors to capitalize on adaptations or expansions of early American achievement. In turn, the rise of international competition in both endeavors has born significant economic and national security consequences that illustrate the importance of fostering hospitable conditions for civil UAS.

\subsection{Car Making: The Engine of Innovation}

The production of the automobile begins as a story of individual rivals locked in a heated yet solitary contest to innovate, and unfolds as a lesson in the strength of group decision engineering. Automobile manufacturing was dominated by U.S. firms going into the second half of the last century, and yet their doom appeared all but certain just a few years ago. The events that transpired during the intervening period show that although innovation by individuals can yield significant technological breakthrough, a whole society must integrate around that technology's processes to truly maximize its value.

The first car was born out of competition to unify chemistry with physics and mathematics to achieve combustion-driven transportation. Two Germans, Carl Benz and Gottlieb Daimler each invented their own versions of an internal combustion engine mounted on wheeled vehicles within months of each other in 1896, working less than 100 miles apart [2]. However, it was roughly 4,000 miles west and 20 years later that Henry Ford's vision of the Model $T$ truly revolutionized transportation by socializing the construction of vehicles on a massive scale.

Ford's breakthrough was in making cars affordable and widely available by adapting mass production techniques from other industries in his design of a modular platform [3]. Yet, such a breakthrough would not have been possible without the advent of the electric utility industry, the socialization of production, and the development of global supply chains, which facilitated the transition from belt-shaft networks of water wheels and coal-powered steam engines, to more efficient unit drive assembly lines powered by large teams of skilled workers and electric motors [4]. Similarly, Edward Budd's development of metal stamping improved assembly line efficiency, and Alfred Sloan's development of a comprehensive business model established the blueprint for how car makers could best market their products and maximize profits by employing ever larger groups in the auto ecosystem [5].

For the first half of the 20th century, American car manufacturers led the global auto industry by adhering to the model established by early leaders like Ford and Sloan, but their inability to sustain innovation compromised their position as a world leader. After World War II, the Japanese government instituted policies to protect the growth of Japanese auto makers by limiting the import of foreign cars to $1 \%$ of the domestic market, while manufacturers continually 
improved production efficiency through the adoption of just-in-time production techniques and decreasing worker specialization in favor of flexibility. By the mid 1960s, Japanese productivity levels matched and surpassed that of its U.S. competitors. A critical factor for maximizing Japanese productivity was the horizontal integration of a highly organized network of component suppliers and assemblers, or keiretsu [6]. By engendering trust through exclusive transactions, close coordination, and information sharing, these keiretsu facilitated high levels of cooperative specialization between sectors of Japan's auto industry [6]. Meanwhile, U.S. production, characterized by vertically integrated and comparatively disorganized supplier-assembler networks remained largely constant into the 1980s.

By 2007, the decline of the U.S. auto industry was drawn into sharp relief in contrast to skyrocketing Chinese production, begging the question of government's role in private industry. The bankruptcy of America's Big Three car makers (General Motors, Chrysler, and Ford) threatened to inflict the loss of one million jobs on the national economy, and the USG was forced to intercede with an $\$ 80$ billion conditional industry bailout in 2009 [7]. The potential for a government bailout was itself a component of the American car industry's brittleness, in that the Big Three knew they could safely rely upon the precedent of bailouts established by the 1980 Chrysler Loan Guarantee Act, and many other instances of the USG rescuing private companies [8].

The American experience in automobile manufacturing illustrates the imperative for continuous innovation, as well as the importance of developing an industrial ecosystem. The early success of American auto makers led the U.S. to become a car-dependent society, but the ability of foreign auto makers to produce better cars at a cheaper price ultimately undermined the U.S. economy. The 2009 bailout demonstrates that while industries cannot be forced to act strategically, public policy plays an important role in the development of technology. Car making also demonstrates the value of complementary technology, in that just as electricity powered mass production, UAS can generate unprecedented amounts of data to power new innovations, industries, and services.

\subsection{Outer Space: The Sky Is not the Limit}

The space race of the mid 20th century resulted in one of humanity's greatest accomplishments in successfully journeying onto the moon and back, via the Apollo Program. Yet, little more than half a century later, the cession of American supremacy in space appears inevitable. What happened?

Driven by the Cold War urgency of winning the battle in space, the Apollo Program was a massive research and development effort with a single focus; getting to the moon first. However, the U.S. lacked a strategic vision of what to do with its hard-won space capability after achieving that feat, and was therefore challenged to follow up its huge investment with coherent progression. Successive U.S. space programs have generally continued on Apollo's trajectory of increasingly complex and aggregated projects [9].

Meanwhile, with the help of U.S. policies, other countries have developed notable space capabilities of their own. During the 1960s, the U.S. led the development of a regulated commercial space industry, with universal standards promoted by organizations like the International Telecommunications Satellite Organization (Intelsat). However, beginning in the early 1970s with the launch of the Open Skies initiative, the progressive deregulation of the satellite industry fueled global competition and gave rise to an increase in small private firms in favor of large conglomerates like Intelsat. At the same time that U.S.-led deregulation helped to increase the number of countries venturing into space, stringent export control laws severely limited the ability of American companies to capitalize on the expanding global market, and the refusal to carry foreign satellites 
aboard U.S. launch vehicles forced other countries to develop their own launch capabilities [10].

While the development or acquisition of a space capability still requires significant national resources, over 50 countries now have satellites in space and 12 have demonstrated a space launch capability. Of the spacecraft launched in 2013, only $27 \%$ were manufactured in the U.S., compared with $41 \%$ in 2009 [11]. In the period $2000-2011,80 \%$ of commercial low-earth orbit satellites and $90 \%$ of commercial geosynchronous earth orbit satellites were launched outside the U.S. [12]. These trends produce interesting outcomes, such as when the Department of Defense (DoD) is forced to rely on Chinese satellites to meet the communications requirements of U.S. Geographic Combatant Commands [13].

Yet, the U.S. has demonstrated its ability to continue making important breakthroughs in space. In contrast to other space capabilities that rely on a small amount of large and hard to defend assets, the GPS (global positioning system) leverages a distributed architecture that lends to the system's resilience by avoiding single points of failure. Yet after 20 years in development, and despite becoming the world's primary navigation utility, GPS has not generated revenue to help offset U.S. investments in space and the system is vulnerable to a variety of threats including spectrum encroachment, jamming, spoofing, and space weather [14], and competing systems [15] are close to overtaking GPS in accuracy and reliability.

Today, space assets are more vital to national security than ever before, but the U.S. ability to guard these assets is also more challenged than ever before [16]. While products of the Cold War have been combined to achieve a monumental feat of global cooperation in the form of the International Space Station [17], emerging rivalries threaten to upset the extraterrestrial balance of power. In particular, China's rapidly expanding space program represents a significant destabilizing force for U.S. space operations [18]. Since terminating its manned space shuttle program in 2011 in exchange for commercial crew and cargo programs, the U.S. now relies on the cooperation and capabilities of private industry and other nations in space [19]. This policy shift has introduced a potential blind spot for the USG, in that it has divested itself of an engineering capability which took generations to attain, and would ostensibly take generations to reclaim. Meanwhile, China's national space program continues to progress along a deliberate and independent trajectory, gaining in sophistication with each mission [20].

As unmanned aircraft technology advances, several key lessons from American experience in space remain salient. First, long-term vision is a prerequisite for guiding the incremental development of scalable technology that will ultimately lead to sustainable capability. Second, establishing a robust regulatory framework that accounts for both national security and revenue generation will ensure that a critical defense capability does not have to be sacrificed due to its cost.

\section{A Brief History of Unmanned Aircraft}

The legacy of unmanned flight is closely tied to international conflict and the evolving requirements of military operations. UA (unmanned aircraft) date back nearly a century to World War I, with their usage increasing in Word War II as pilot training aids and explosive ordinance delivery systems [21]. As the conclusion of the Second World War segued to a more protracted Cold War, ISR (intelligence, surveillance, and reconnaissance) became a vital national capability. With the downing of U2 spy planes and capture or death of their pilots in 1959 over the Soviet Union and Cuba in 1962, the value of unmanned reconnaissance aircraft was clear, and the Air Force and Central Intelligence Agency coordinated through the NRO (National Reconnaissance Office) to develop multiple variants of the Ryan Firebee, which were flown extensively during the Vietnam War [22]. While the 
intelligence community was a significant contributor to the development of unmanned capability, via the NRO, through the 1970s and into the 1980s, the U.S. reduced its focus on UAS in favor of satellite reconnaissance, and by 1991, the U.S. looked to Israel's Pioneer unmanned platform for ISR support over Iraq [23]. While satellites are a vital component of national intelligence capability, they are constrained in their ability to adapt to mobile objects of interest. The re-commissioning of SR-71 Blackbirds into military service in the mid 1990s demonstrates the unchanging need for a responsive and flexible reconnaissance capability, which satellites simply cannot fulfill in light of their fixed orbits [24].

As a result of Pioneer's significant contributions during the Persian Gulf War, the DoD increased its own research and development efforts for unmanned systems, and fielded the Predator in operations over the Balkan Peninsula in the mid 1990s. Imagery generated by the Predator and other remote sensing assets was so useful during negotiations of the 1995 Dayton Peace Accords that the NIMA (national imagery and mapping agency) was created the following year [25]. The USG continued to increase its investment in UAS into the new millennium, and NIMA's transformation into the NGA (national geospatial-Intelligence agency) in 2003 represents the vital role that remote sensing has come to play in national security.

While NGA is the USG's lead integrator of remote sensing imagery, including that collected with unmanned aircraft, each of the military services now employs a large and diverse fleet of UAS for a variety of long-endurance and high-risk missions [26]. In fact, the DoD's inventory of UA is fast approaching that of manned aircraft [27], which are generating vast amounts of data. The operation of just one Global Hawk UAS generates 500 megabits of data per second, which is about five times the satellite-relayed data flow or bandwidth used by the entire U.S. military during the Persian Gulf War [28]. The explosion in data throughput requirements brought on by UAS capability has introduced its own set of challenges, as the expansion of fiber optic cable networks have stunted the growth of satellite bandwidth. During early deployments at the onset of Operation Enduring Freedom in Afghanistan, operators of the Global Hawk frequently had to lower its video resolution and cope with fuzzier images in order to avoid overwhelming the capacity of communication systems. Indeed, the availability of satellite bandwidth will continue to be an important consideration for both military and civil UAS operations going forward.

While the technical achievements of UAS in war are significant, it is important to note that their use for kinetic operations or direct strike missions is not without controversy [29]. The United Kingdom's Ministry of Defence has acknowledged that unmanned direct strikes may actually undermine military campaigns by giving adversaries a "potent propaganda weapon" [30]. The precedent which the U.S. and its coalition partners have established by using UAS overseas for targeted killings raises important questions about international regulation in light of recent developments in Pakistan and elsewhere [31].

While the military service record of UAS for carrying out dull, dirty, and dangerous missions is well-established, their employment for non-military use represents an area of potentially enormous expansion. Within non-military UAS applications, the FAA delineates three broad civil categories: public (i.e., governmental), commercial, and private. UAS use is growing rapidly in each of these areas, as we will further explore below.

Employing UAS as remote sensors holds promise for many public services; because it enables civilian government agencies to collect information that otherwise would be prohibitively expensive to gather using manned aircraft or satellite surveillance. Such a capability can be particularly valuable in safeguarding critical infrastructure and responding to natural disasters. For example, the early detection and 
continuous tracking of forest fires is a perennial challenge due to the inaccessible and mountainous terrain in which many fires occur. However, by using UAS to detect the outbreak and monitor the path of forest fires, state and federal responders are able to safely and more effectively stop their spread [32]. Similarly, law enforcement officers are beginning to use drones to detect illegal activities and track perpetrators, a capability that was historically limited by the cost of manned helicopters [33]. The Department of Homeland Security has been using UAS since 2004 to help close the gap in its ability to monitor isolated portions of the southern U.S. land and littoral borders, and today operates a fleet of 10 UAS platforms [34]. UAS can also play a pivotal role in environmental monitoring and enhancing our ability to understand and predict extreme weather phenomena by enabling scientists to collect more precise and complete climatic data, with the National Aeronautic and Space Administration's Helios project being one notable example [35]. Similarly, natural resource management efforts, including analysis of the effects of livestock grazing on the health of rangeland ecology are benefitting from UAS capabilities [36]. Remote sensing via UAS is also enabling federal and state Departments of Transportation to conduct traffic surveillance, assess road conditions, analyze travel patterns, and detect emergencies [37]. These examples are only a glimpse of the many potential benefits to be gained by the public use of UAS.

Commercial applications for UAS are equally varied, with only a small portion of potential uses having been realized thus far as a result of regulatory restriction. In Japan, $90 \%$ of all precision pesticide-spraying is done with a fleet of over 2,500 unmanned helicopters [38]. Other examples include real estate mapping, aerial news and sporting event coverage, movie and television production, and cargo transportation. As UAS technology becomes more affordable, it is reasonable to expect that pervasive remote sensing itself will be marketed as a commodity in much the same way that smart phones have given rise to novel data-driven services [39].

Private UAS use carries on a well-established tradition of model aircraft piloting for recreational purposes, but also represents a significant threat if used for malicious purposes. As we have demonstrated in earlier research, UAS represent an important component in IMDs (coined as improvisational malignant devices), which are characterized by low levels of sophistication and required resources, yet can yield significant destabilizing impact. While the U.S. has demonstrated some success in averting plans to employ UAS in malicious acts [40], many recent events underscore the challenges associated with quickly detecting such acts as they occur [41].

\section{Comparing U.S. and International Regulations for UAS}

Having established the comparatively long history of UA operations, and the wide variety of applications into which their employment has expanded, we turn to the policies governing their use. While Congress has mandated that regulations be developed to govern UAS operation in the NAS (national airspace system) before the end of this year, the policy of the FAA (federal aviation administration) for the last ten years has been to broadly prohibit the operation of UAS for public or commercial purposes, instead regulating their exceptional limited use through special air worthiness certificates and certificates of waiver or authorization [42].

With regard to private operations, FAA's guidance for model aircraft from 1981 has been applied to UAS [43]. However, such an advisory relies largely on the ability of local law enforcement to detect the misuse of UAS, and does not establish a systematic mechanism for addressing misuse or malicious use. There are a variety of complex dynamics at play in UAS regulation. Indeed, any robust regulatory framework for unmanned aircraft operations must 
address the blind spot of maliciously-employed UAS as an emerging threat vector. To be sure, the development of policy for the broad civilian use and commercialization of domestic unmanned flight is no simple task. The difficulty of this task is compounded by the need to ensure harmony with a variety of contending issues, not to mention the technical complexity of UAS themselves.

While the FAA has rightly focused on the practical mechanics of safe operation, such as sense and avoid protocols, airworthiness standards, and pilot certification [44], a host of broader existential challenges also loom. For example, the case law for air rights establishes that the owner of a property also owns and is entitled to exclusive use of as much of the uncontrolled airspace above that property as they are reasonably capable of using [45].With the advent of UAS, property owners are now capable of using much more of their airspace. Therefore, a careful balance must be struck to ensure that public and commercial UAS are able to operate effectively without infringing on citizens' rights to their own airspace. Meanwhile, defining what constitutes acceptable use of one's airspace is also a central concern. As the State Department has encountered resistance from host nations regarding the U.S. authority to collect and disseminate data from the airspace above its embassies [46], it is clear that enhanced data collection capability will require more sophisticated forms of regulation.

In addition to reconciling potential conflict with existing law, UAS regulations must also complement the FAA's larger NextGen (next generation) Air Transportation System transformation effort [47]. NextGen aims to leverage satellite communication to supersede the currently overburdened radar systems in order to increase air traffic volume, safety, and efficiency. But, how to achieve these goals while integrating UAS is an open question, albeit one that appears to lend itself well to a Big Data paradigm based on effective management of increased data availability. In the NextGen system, more networked communication between air traffic controllers, aircraft pilots, and aircraft themselves will result in much larger amounts of data being generated, which raises important socio-techno concerns. Broadly speaking, we must determine how the roles of man and machine in air traffic control operations should evolve. More specifically, we must determine whether trends such as the Federal Communications Commission's support of an industry-wide shift from the $\mathrm{Ku}$ to Ka frequency bands for satellite links with UAS and other earth stations is introducing brittleness into the national communications infrastructure in light of Ka band's demonstrated vulnerability to signal attenuation in moist atmospheric conditions [48].

Although tenets of international UAS regulation are perhaps even more ambiguous than those of U.S. policy, a review of legal precedent is instructive. The basic freedoms of the air established in the Chicago Convention and promoted by the UN (United Nations) ICAO (international civil aviation organization) address issues of passenger aircraft, providing that states may grant each other the privileges of flying across, landing in, taking on, and putting down traffic between states [49]. The ICAO has identified preliminary steps to bring UAS under the Chicago Convention rubric, but the transformative nature of the technology may warrant an even more fundamental restructuring of the framework governing air operations.

In this regard, the principles guiding maritime affairs offer insight. In particular, Admiralty Law for maritime navigation and shipping establishes that a ship's flag determines its source of law, such that vessels traveling outside their national waters remain subject to their home law. Assuming regulations develop for UAS in national borders, applying the Admiralty principle to unmanned operation in international airspace is logical. The UN Convention on the LOS (Law of the Sea) [50] establishes territorial seas in which the sovereignty of a state is 
extended 12 miles beyond its shore, including airspace over water. Foreign vessels are permitted innocent or transitory passage through another nation's territorial waters, but solely for the purpose of traversal. Notably, conducting any survey activities during the passage of another nation's territorial waters is construed as prejudicial to the peace of that nation, and therefore illegal. The Convention also establishes EEZs (exclusive economic zones) extending 200 nautical miles from a sovereign nation's shore in which that nation enjoys exclusive commercial and exploratory rights. Any area outside the territorial seas and EEZs are designated as the high seas, and are open to all states for peaceful purposes.

Extrapolating from the LOS, international airspace correlates neatly to the high seas and controlled national airspace correlates to territorial seas, but what about exclusive economic zones? As remote sensing capabilities expand with UAS, public and commercial applications requiring global circumnavigation will undoubtedly emerge. U.S. national airspace above 60,000 feet is currently designated Class E, the least regulated of any of the six airspace classes. Looking above the atmosphere, the Outer Space Treaty establishes that all nations and non-governmental organizations have the right to freely explore outer space without any discrimination [51]. From this context, an upper limit of nationally controlled airspace above which nations could freely navigate UAS is conceivable.

The employment of UAS across international borders for military operations is governed by established laws of armed conflict such as the 1949 Geneva Convention, yet new precedent is unquestionably being established by the U.S. amidst its global pursuit of Al-Qa'ida and affiliated entities [52]. Whether the protracted deployment of UAS for worldwide low intensity applications of force is indeed conducive to a stable international system is somewhat doubtful. In contrast, the ATS (Antarctic treaty system) offers a more viable alternative. It establishes that as the only continent with no recognized or disputed claims of sovereignty, Antarctica will be used solely for peaceful purposes, namely scientific investigation and cooperation between its 50 signatories. While conflicts regarding the ATS do arise, such as the dispute between militant conservationists and whale "research" vessels [53], the cooperative spirit of the ATS lends credibility to a similarly open arrangement for globally operating UAS. Enabling the use of UAS for pervasive remote sensing increases our data collection capacity, this in turn increases our understanding of complex phenomena and contributes to enhanced resilience. However, addressing the privacy and security ramifications of a global pervasive remote sensing capability will be of chief importance to future international UAS regulations.

Although the exact form of UAS regulation has yet to crystallize, several facts are clear. First, the de-facto ban on civil UAS operations in the U.S. has confined progression. It is estimated that growth of the civil UAS industry will generate 70 thousand jobs in the first three years of integration and $\$ 80$ billion over the next ten years, with each day of non-integration representing nearly a $\$ 28$ million loss [54]. Indeed, the world's top two producers of commercial UAS are outside the U.S., and in an ironic turn of events, the platform being touted as the "Model $\mathrm{T}$ of unmanned aircraft"-The DJI Phantom-is being produced in the Silicon Valley of the East; Shenzhen, China [55]. Second, as UAS become more widely available, their potential to destabilize brittle systems through accidental misuse or deliberate malicious action will increase. Although they are areas for future research, geo-fencing and mandatory device registration are two possible components of a technical solution to UAS malicious use. More generally, developing policies and regulations that foster innovation and harness UAS as pervasive remote sensors can both mitigate the potential threat of blind spots posed by such technology while leveraging it to enhance resilience. 


\section{Conclusion}

We are at a critical phase in the proliferation of unmanned aircraft systems as a transformative technology, and the shape of regulatory policy for the broad civil use of these systems will be a determining factor in the fate of pervasive remote sensing as a strategic national capability. UAS offer a potential doorway to pervasive remote sensing in a BDP. But, in order to unlock the door, public policy must catch up with technology. Our historical hindcasting of trends in international space capability and automobile manufacturing underscore the influence that policy and regulation exert on the development of transformative technology. Through these cases, the potential for blind spots in public policy to introduce brittleness into critically important national capabilities is clear. Conversely, the technological advantages of UAS have the potential to yield vast increases in the amount of data available to engineer more sound decisions, including decisions regarding the prevention and mitigation of IMDs.

This increase in available data and enhanced decision engineering is at the core of a BDP for pervasive remote sensing, and can improve our approach to a variety of missions, including CIP, homeland defense, law enforcement, resource management, environmental stewardship, and disaster response. Pervasive remote sensing will drive the advance of analytics in a host of commercial and research fields, as it makes more data available. However, this potential can only be realized if the proliferation of UAS is managed proactively and wisely. In light of a BDP's value in ameliorating these areas of brittleness, we look forward to future work exploring what other areas of strategic interest might similarly benefit from such a paradigm.

\section{References}

[1] Zaslavsky, A., Perera, C., and Georgakopoulos, D. 2013. "Sensing as a Service and Big Data." arXiv Preprint arXiv:1301.0159.

[2] Dorrington, L. 2011. "125th Anniversary of the
Automobile: Karl Benz and Gottlieb Daimler Put the World on Wheels." Autoweek. http://autoweek.com/article/car-news/125th-anniversary-a utomobile-karl-benz-and-gottlieb-daimler-put-world-whe els-0.

[3] Alizon, F., Shooter, S. B., and Simpson, T. W. 2009. "Henry Ford and the Model T: Lessons for Product Platforming and Mass Customization." Design Studies 30: 588-605.

[4] Boff, R. B. D. 1967. "The Introduction of Electric Power in American Manufacturing." The Economic History Review 20: 509-18.

[5] Wells, P., and Nieuwenhuis, P. 2012. "Transition Failure: Understanding Continuity in the Automotive Industry." Technological Forecasting and Social Change 79: 1681-92.

[6] Dyer, J. H. 1996. "Specialized Supplier NetWorks as a Source of Competitive Advantage: Evidence from the Auto Industry." Strategic Management Journal 17: 271-91.

[7] D. o. t. Treasury, ed. 2014. The Department of the Treasury Office of Financial Stability-Troubled Asset Relief Program Citizens' Report Fiscal Year 2014. Washington, DC.

[8] Schmidt, J. N. K. K. 2009. "History of U.S. Government Bailouts." ProPublica. http://www.propublica.org/special/government-bailouts\#t arp.

[9] Pawlikowski, E., Loverro, D., and Cristler, T. 2012. "Space: Disruptive Challenges, New Opportunities, and New Strategies.” Strategic Studies Quarterly 6: 27-54.

[10] Hertzfeld, H. R. 2007. "Globalization, Commercial Space and Spacepower in the USA." Space Policy 23: 210-20.

[11] Satellite Industry Association (SIA). State of the Satellite Industry Report. Washington, DC.

[12] Hosted Payloads Alliance (HPA). 2012. The Impact of U.S. Space Transportation Policy on the Commercially Hosted Payload Enterprise. Illinois.

[13] Gruss, M. 2013. "Pentagon Lease of Chinese Bandwidth Arouses Concern." Space News, ed.

[14] Gao. 2013. "GPS Disruptions: Efforts to Assess Risks to Critical Infrastructure and Coordinate Agency Actions Should Be Enhanced." U. S. G. A. Office, Ed., ed. Washington, DC.

[15] Cojocaru, S., Birsan, E., Batrinca, G., and Arsenie, P. 2009. "GPS-Glonass-Galileo: A Dynamical Comparison.” Journal of Navigation 62: 135-50.

[16] Rumsfeld, D., Andrews, D., Davis, R., Estes, H., Fogleman, R., and Garner, J. 2001. Report of the Commission to Assess United States National Security Space Management and Organization. Government Printing Office, Washington, DC. 
[17] DeLucas, L. J. 1996. "International Space Station.” Acta Astronautica 38: 613-9.

[18] Martel, W. C., and Yoshihara, T. 2003. "Averting a Sino-U.S. Space Race.” The Washington Quarterly 26 (9): 19-35.

[19] Logsdon, J. M. 2011. "Change and Continuity in US Space policy." Space Policy 27: 1-2.

[20] Strickland, E. 2014. "The Next Space Super-Power." IEEE Spectrum 51: 48-51.

[21] Newcome, L. R. 2005. Unmanned Aviation: A Brief History of Unmanned Aerial Vehicles: Pen and Sword.

[22] Sullivan, J. M. 2005. "Revolution or Evolution? The rise of the UAVs." In Proceedings of 2005 International Symposium on Weapons and Wires: Prevention and Safety in a Time of Fear in Technology and Society, 94-101.

[23] Ehrhard, T. P. 2010. Air Force UAV's: The Secret History. Mitchell Institute for Airpower Studies, Arlington, VA.

[24] SASC/HASC. 1994. National Defense Authorization Act and Military Construction Authorization Act for Fiscal Year 1995 - Conference Report. U. Congress, Ed., ed. Washington, DC: Congressional Record.

[25] NGA. 2011. The Advent of the National Geospatial-Intelligence Agency. O. o. t. H. Historian, Ed., ed. St. Louis, MO.

[26] OSD. 2005. Unmanned Aircraft Systems Roadmap 2005-2030. D. o. Defense, Ed., ed. Washington, DC.

[27] O. AT\&L. 2012. Department of Defense Report to Congress on Future Unmanned Aircraft Systems Training, Operations, and Sustainability. D. o. Defense, Ed., ed. Washington, DC.

[28] G. Jaffe. 2002. "Military Feels Bandwidth Squeeze As the Satellite Industry Sputters." Wall Street Journal. Available:

http://www.wsj.com/articles/SB1018389902229614520.

[29] Stanford/NYU. "Living Under Drones: Death, Injury, and Trauma to Civilians from U.S. Drone Practices in Pakistan." International Human Rights and Conflict Resolution Clinic at Stanford Law School and Global Justice Clinic at NYU School of Law2012.

[30] MoD, U. 2011. Joint Doctrine Note 2/11 The U.K. Approach to Unmanned Aircraft Systems. M. o. Defence, Ed., ed. Shrivenham, United Kingdom: Development, Concepts and Doctrine Centre.

[31] Mazzetti, M., and Apuzzo, M. 2015. "Deep Support in Washington for C.I.A.'s Drone Missions.” In New York Times, ed. New York, NY.

[32] Casbeer, D. W., Beard, R. W., McLain, T. W., Ming, L. S., and Mehra, R. K. 2005. "Forest Fire Monitoring with Multiple Small UAVs." In Proceedings of the Conference American Control, 3530-5.
[33] Horgan, J. 2013. "The Drones Come." National Geographic (March) 122-33.

[34] Gertler, C. H. J. 2010. "Homeland Security: Unmanned Aerial Vehicles and Border Surveillance ." C. R. Service, Ed., ed. Washington DC.

[35] Dunbabin, M., and Marques, L. 2012. "Robots for Environmental Monitoring: Significant Advancements and Applications." Robotics \& Automation Magazine, IEEE 19: 24-39.

[36] Rango, A., Laliberte, A., Herrick, J. E., Winters, C., Havstad, K., and Steele, C. 2009. "Unmanned Aerial Vehicle-Based Remote Sensing for Rangeland Assessment, Monitoring, and Management." Journal of Applied Remote Sensing 3: 033542-033542-15.

[37] Puri, A. 2005. "A Survey of Unmanned Aerial Vehicles (UAV) for Traffic Surveillance.” Department of Computer Science and Engineering, University of South Florida.

[38] Council, N. R. 2014. Autonomy Research for Civil Aviation: Toward a New Era of Flight. Washington, DC: The National Academies Press.

[39] Wei, W. H., and Wen, B. H. 2011. “A Reservation-Based Smart Parking System." Presented at the 2011 IEEE Conference on Computer Communications Workshops (INFOCOM WKSHPS).

[40] Bidgood, J. 2014. "Massachusetts Man Gets 17 Years in Terrorist Plot.” In New York Times, ed., 2012.

[41] Shear, M. S. M. “A Drone, Too Small for Radar to Detect, Rattles the White House." In New York Times, ed. New York City, NY.

[42] Wolf, H. G. 2013. "Unmanned Aircraft Systems Integration into the National Airspace." Presented at the Conference Aerospac.

[43] FAA. 1981. Department of Transportation Federal Aviation Administration Advisory Circular 91-57 Model Aircraft Operating Standards. U. S. D. o. Transportation, Ed., ed. Washington, DC.

[44] F. A. Administration. 2013. Integration of Civil Unmanned Aircraft Systems in the National Airspace System Roadmap. U. S. D. o. Transportation, Ed., First Edition ed. Washington DC: FAA Communications.

[45] Madrigal, A. 2012. "If I Fly a UAV Over My Neighbor ed's House, Is It Trespassing?" The Atlantic. Available http://www.theatlantic.com/technology/archive/2012/10/i f-i-fly-a-uav-over-my-neighbors-house-is-it-trespassing/2 63431/.

[46] S. S. S. Olivier. 2012. "China Has No Good Answer to the U.S. Embassy Pollution-Monitoring." The Atlantic. Available:

http://www.theatlantic.com/international/archive/2012/06 /china-has-no-good-answer-to-the-us-embassy-pollutionmonitoring/258447/.

[47] Dyk, R. N. V., Pariseau, D. H., Dodson, R. E., Martin, B. 
T., Racliffe, A. T., and Austin, E. A. 2012. "Systems integration of Unmanned Aircraft into the National Airspace: Part of the Federal Aviation Administration Next Generation Air Transportation System.” Presented at the 2012 IEEE Symposium on Systems and Information Design (SIEDS).

[48] Sala, S., Zennaro, M., Sokol, L., Miao, A., Spousta, R., and Chan, S. 2013. "Mitigation of Rain-Induced Ka-Band Attenuation and Enhancement of Communications Resiliency in Sub-Saharan Africa."

[49] ICAO. 2004. Manual on the Regulation of International Air Transport-Second Edition. I. C. A. Organization, Ed., ed. Montreal, CA.

[50] United Nations Convention on the Law of the Sea, U. Nations, 1982.

[51] Jakhu, R. S., and Pelton, J. N. 2014. "The Global Legal Guidelines Governing Satellite Deployment.” In Small
Satellites and Their Regulation, ed.: Springer, 43-8.

[52] Heyns, C. 2013. "Report of the Special Rapporteur on Extrajudicial, Summary or Arbitrary Executions." Vol. A/68/382, U. N. G. Assembly, Ed., ed. New York, NY: U.N. General Assembly.

[53] Rothwell, D. R. 2013. "The Polar Regions and the Development of International Law: Contemporary Reflections and Twenty-First Century Challenges." The Yearbook of Polar Law Online 5: 233-51.

[54] Vasigh, D. J. B. 2013. The Economic Impact of Unmanned Aircraft Systems Integration in the United States. Association for Unmanned Vehicle Systems International, Arlington, VA.

[55] Murphy, J. N. C. 2014. "Who Builds the World's Most Popular Drones?" The Wall Street Journal. Available : http://www.wsj.com/articles/who-builds-the-worlds-most -popular-drones-1415645659. 